\title{
Sakarya Nehri Su Kalitesinin İstatistiksel Veri Değerleme Yöntemleri Kullanılarak Değerlendirilmesi
}

\author{
${ }^{* 1}$ Beytullah Eren ve ${ }^{1}$ Ahmet Çelebi \\ ${ }^{1}$ Sakarya Üniversitesi Çevre Mühendisliği Bölümü, Sakarya, Türkiye
}

\begin{abstract}
:
Rivers are crucial freshwater systems for the continuation of aquatic life. Water quality of rivers is an important parameter for the health of all living things and for a sustainable environment. With the increase in population and developments in industrialization, the water quality of the rivers, which are generally considered as the receiving environment for the treated wastewater, is continuously deteriorating. In order to keep the river water quality under control, it is important to use easily understandable water quality evaluation method in terms of parameters determining water quality. In this study, water quality data obtained from 3 different flow observation stations (Pamukova, Doğançay and Adatepe stations) which were collected on monthly basis for 5 years were used in the evaluation of water quality of Sakarya River. Sakarya River water quality classes were determined using statistical data evaluation methods (Hazen, Weibull and Logarithmic methods). Water quality classes were examined according to each method which was general conditions (temperature, $\mathrm{Ph}$, Conductivity), oxygenation (Dissolved Oxygen, Biological Oxygen Demand, Chemical Oxygen Demand), nutrient (Ammonia Nitrogen, Nitrite Nitrogen, Nitrate Nitrogen, Total Kjeldahl Nitrogen, Total phosphorus) parameters. As a result, it is understood that the use of statistical data evaluation methods for the decision-makers for surface water quality classification is an important and practical method.
\end{abstract}

Keywords: Water quality, Statistical data evaluation methods (Hazen, Weibull, and Logarithmic), Sakarya River.

\section{Özet:}

Nehirler canlı yaşamının devamı için vazgeçilmez tatlı su sistemleridir. Nehirlerin su kalitesi tüm canlıların sağlığı ve sürdürülebilir bir çevre açısından önemli bir parametredir. Nüfusun artması ve sanayileşmedeki gelişmelerle birlikte çoğunlukla arıtılmış atıksular için alıcı ortam olarak değerlendirilen nehirlerin su kalitesi sürekli olarak kötüleşmektedir. Nehir su kalitesinin sürekli kontrol altında tutmak için, su kalitesini belirleyen parametreler açısından kolaylıkla hesaplanabilen ve anlaşılabilir su kalitesi değerlendirme yöntemi kullanılması önem arz etmektedir. Bu çalışmada Sakarya Nehri su kalitesinin değerlendirilmesinde, nehir üzerinde kurulu 3 ayrı akım gözlem istasyonundan (Pamukova, Doğançay ve Adatepe istasyonları) 5 yıl süreyle aylık olarak alınan numunelerden elde edilen 60 aylık su kalitesi verileri kullanılmıştır. Sakarya Nehri su kalitesi sınıfları istatistiksel veri değerleme yöntemleri (Hazen, Weibull ve Logaritmik yöntemler) kullanılarak belirlenmiştir. Su kalitesi sınıfları her bir yönteme göre genel şartlar (Sıcaklık, pH, İletkenlik), oksijenlendirme (Çözünmüş Oksijen, Biyolojik Oksijen İhtiyacı, Kimyasal Oksijen İhtiyacı), nütrient (Amonyak Azotu, Nitrit Azotu, Nitrat Azotu, Toplam Kjeldahl Azotu, Toplam Fosfor) parametreleri açısından incelenmiştir. Sonuç olarak istatistiksel veri değerleme yöntemlerinin karar vericiler için yüzeysel su kalitesi sınıflandırma amacıyla kullanımının önemli ve pratik bir yöntem olduğu anlaşılmıştır.

Anahtar Kelimeler: Su kalitesi, İstatistiksel veri değerleme yöntemleri (Hazen, Weibull ve Logaritmik), Sakarya Nehri.

*Sorumlu Yazar: B. EREN, Sakarya Üniversitesi, Mühendislik Fakültesi, Çevre Mühendisliği Bölümü, Serdikant» Sakarya, Türkiye. E-mail: beren@sakarya.edu.tr, Tel: 02642955642. 


\section{Giriş}

Su yeryüzünde yaşayan tüm canlı formları için en temel kaynaklardan biridir. Temiz su insan sağlı̆̆ına zarar verecek herhangi bir kimyasal madde ve canlı mikroorganizma içermemelidir. Dünyadaki büyüme ve gelişme ile birlikte yüzeysel sular çok çeşitli kaynaklardan gelen yoğun kirleticilerle kirlenmektedir. Yüzeysel su kaynaklarının kimyasal, fiziksel ve biyolojik özelliklerini belirleyen buharlaşma, havzanın yapısı, atmosfer, jeoloji, endüstriyel aktiviteler, evsel ve/veya tarımsal akışlar gibi birçok parametre mevcuttur [1].

Yüzeysel su kaynaklarının kirlenmesinde meydana gelen artış içme suyu temin edilen su kaynaklarının kalitesinin bozulmasına yol açmaktadır. Bunun doğal bir sonucu olarak insan sağlı̆̆1 olumsuz bir şekilde etkilenmekte ve sucul yaşamın dengesi bozulmaktadır. Birleşmiş Milletler Gelişme Programı'na göre dünya üzerinde yatan hastaların \%50'si su kaynaklı hastalıklardandır. Yine aynı rapora göre beş yaşın altındaki çocuk ölümlerinin yaklaşı \% 20'si su kaynaklı hastalıklardandır [2]. Yüzeysel su kaynaklarının temiz kalmasını sağlamak için su kalitesinin etkili bir şekilde kontrol edilmesi ve yönetilmesi büyük önem arz etmektedir.

Bütün ülkeler kendi içme suyu kalitesi kriterlerini belirleyebildiği gibi, Dünya Sağlik Örgütü (WHO) ve AB (Avrupa Birliği) gibi kuruluşlarda içme sularında bulunan zararlı maddeler için sınır değerler belirlemiştir. Ancak bu parametrelerin bu konuda çalışan uzmanlar tarafından tek tek ele alınarak değerlendirilmesi ve yorumlanması zor ve zaman alıcı bir süreçtir. Bu nedenle son zamanlarda yapılan birçok çalışmada su kalitesinin daha pratik, anlaşılabilir ve kolay yorumlanabilir şekilde değerlendirilmesi üzerine yoğunlaşılmıştır [3-6].

Bu çalışmada, Sakarya Nehri üzerinde kurulu Pamukova, Doğançay ve Adatepe akım gözlem istasyonlarından 2012-2017 yılları arasında elde edilen su kalitesi verileri değerlendirilmiştir. Beş yıl ve 60 aylık ölçümden oluşan su kalitesi verileri genel şartlar (Sicaklık, pH, İletkenlik), oksijenlendirme parametreleri (Çözünmüş Oksijen, Biyolojik Oksijen İhtiyac1, Kimyasal Oksijen İhtiyac1) ve nütrient (besin elementleri) parametreleri (Amonyak Azotu, Nitrit Azotu, Nitrat Azotu, Toplam Kjeldahl Azotu, Toplam Fosfor)'ni içermektedir. Çalışma kapsamında 30 Kasım 2012 Tarih ve 28483 Sayll Resmi Gazete'de yaylnlanan "Yüzeysel Su Kalitesi Yönetimi Yönetmeliği”nde yer alan Istatistiksel Veri Değerlendirme Yöntemleri (Hazen, Weibull ve Logaritmik yöntem) kullanılarak Sakarya Nehrinin belirtilen parametreler açısından su kalitesi sınıfları belirlenmiştir.

\section{2. Çalışma Alanı}

Sakarya Nehri Türkiye'nin kuzeybatısında yer almakta ve yaklaşık $810 \mathrm{~km}$ uzunluğu ile Türkiye'nin üçüncü uzun nehridir. Nehrin genişliği 60-150 m arasında değişmektedir. Sakarya Nehri, Eskişehir ilinde bulunan çifteler ilçesinin yaklaşık $3 \mathrm{~km}$ güneydoğusundan doğar, birçok dere ile beslenir ve kuzeye doğru akarak Karasu Bölgesi'nden denize dökülür (Şekil 1) [7]. Sakarya Nehri'nin önemli yan kolları başta Porsuk ve Ankara çayı olmak üzere Seydisuyu, Çarksuyu, Karasu, Girmir çayı, Göynük çayı, Mudurnu çayı ve Göksu'dur. Havza içinde yer alan iller Ankara, Eskişehir, Kütahya, Bilecik ve Sakarya'dır [8]. Nehrin, minimum debisi $30 \mathrm{~m}^{3} / \mathrm{s}$, ortalama debisi $193 \mathrm{~m}^{3} / \mathrm{s}$ ve maksimum debisi $996 \mathrm{~m}^{3} / \mathrm{s}$ olarak belirlenmiştir [9]. Havza toplam 
drenaj alanı, yaklaşık $56.504 \mathrm{~km}^{2}$ ile Türkiye yüz ölçümünün \% 7,6'sına karşılık gelmektedir. Havza hidrolojik olarak, yukarı, orta ve aşağı Sakarya havzası olmak üzere üç bölgeye ayrılmaktadır [7]. Nehir hızla artan nüfus ve endüstrileşmeyle birlikte kentsel, tarımsal ve endüstriyel faaliyetler sonucu oluşan atıksuların nehre deşarj edilmesi nedeni ile uzun yıllardır kirliliğe maruz kalmıştır.

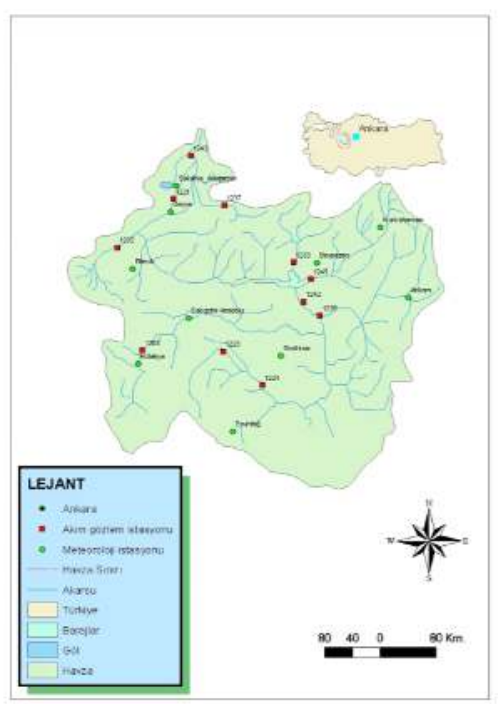

Şekil 1. Sakarya Nehri havzası ve lokasyonu [10]

\section{Materyal ve Metot}

$\mathrm{Bu}$ çalışmada, Sakarya Nehri su kalitesi sınıflarının belirlenmesinde nehir üzerinde yer alan 3 ayrı akım gözlem istasyonundan (Pamukova, Doğançay ve Adatepe) 2012-2017 yılları arasında elde edilen 5 yıl ve 60 aylık su kalitesi verileri kullanılmıştır. Verilerin değerlendirilmesinde "30 Kasım 2012 tarih ve 28483 sayll Resmi Gazete'de yayınlanan Yüzeysel Su Kalitesi Yönetimi Yönetmeliği'nde" yer alan Istatistiksel Veri Değerlendirme Yöntemleri (Hazen, Weibull ve Logaritmik yöntem) kullanılmıştır. İstatistiksel veri değerleme yöntemlerinden elde edilen sonuçlar Tablo 1'de sunulan ve aynı yönetmeliğin Ek-5'inde yer alan "Kıtaiçi Yüzeysel Su Kaynaklarının Sınıflarına Göre Kalite Kriterleri” ile karşılaştırılmış ve Sakarya Nehri su kalite sınıfları belirlenmiştir.

Tablo 1. Kıta içi Yüzeysel Su Kaynaklarının Sınıflarına Göre Kalite Kriterleri [11]

\begin{tabular}{|c|c|c|c|c|}
\hline \multirow{2}{*}{ Su Kalite Parametreleri } & \multicolumn{4}{|c|}{ Su Kalite Sınıfları } \\
\hline & I & II & III & IV \\
\hline \multicolumn{5}{|c|}{ Genel Șartlar } \\
\hline Sicaklık $\left({ }^{\circ} \mathrm{C}\right)$ & $\leq 25$ & $\leq 25$ & $\leq 30$ & $>30$ \\
\hline $\mathrm{pH}$ & $6,5-8,5$ & $6,5-8,5$ & $6,0-9,0$ & $6,0-9,0$ dişında \\
\hline İletkenlik $(\mu \mathrm{S} / \mathrm{cm})$ & $<400$ & $400-1000$ & $1001-3000$ & $>3000$ \\
\hline \multirow{3}{*}{ Renk } & RES $436 \mathrm{~nm}: 1.5$ & RES $436 \mathrm{~nm}: 3$ & RES 436 nm: 4.3 & RES 436 nm: 5 \\
\hline & RES $525 \mathrm{~nm}: 1.2$ & RES $525 \mathrm{~nm}: 2.4$ & RES $525 \mathrm{~nm}: 3.7$ & RES $525 \mathrm{~nm}: 4.2$ \\
\hline & RES $620 \mathrm{~nm}: 0.8$ & RES $620 \mathrm{~nm}: 1.7$ & RES $620 \mathrm{~nm}: 2.5$ & RES $620 \mathrm{~nm}: 2.8$ \\
\hline
\end{tabular}


Tablo 2. Kıta içi Yüzeysel Su Kaynaklarının Sınıflarına Göre Kalite Kriterleri (Devamı) [11]

\begin{tabular}{|c|c|c|c|c|}
\hline \multirow{2}{*}{ Su Kalite Parametreleri } & \multicolumn{4}{|c|}{ Su Kalite Sınıfları } \\
\hline & I & II & III & IV \\
\hline \multicolumn{5}{|c|}{ (A) Oksijenlendirme Parametreleri } \\
\hline $\begin{array}{l}\text { Çözünmüş oksijen } \\
\qquad\left(\mathrm{mg} \mathrm{O}_{2} / \mathrm{L}\right)^{\mathrm{a}}\end{array}$ & $>8$ & $6-8$ & $3-6$ & $<3$ \\
\hline Oksijen doygunluğu $(\%)^{\mathrm{a}}$ & 90 & $70-90$ & $40-70$ & $<40$ \\
\hline $\begin{array}{c}\text { Kimyasal oksijen ihtiyacı (KOİ) } \\
(\mathrm{mg} / \mathrm{L})\end{array}$ & $<25$ & $25-50$ & $50-70$ & $>70$ \\
\hline $\begin{array}{c}\text { Biyolojik oksijen ihtiyacı }\left(\mathrm{BOI}_{5}\right) \\
(\mathrm{mg} / \mathrm{L})\end{array}$ & $<4$ & $4-8$ & $8-20$ & $>20$ \\
\hline \multicolumn{5}{|c|}{ B) Nutrient (Besin Elementleri) Parametreleri } \\
\hline Amonyum azotu (mg NH$\left.{ }_{4}^{+}-\mathrm{N} / \mathrm{L}\right)$ & $<0,2^{\mathrm{b}}$ & $0,2-1^{\mathrm{b}}$ & $1-2^{b}$ & $>2$ \\
\hline Nitrit azotu $\left(\mathrm{mg} \mathrm{NO}_{2}^{-}-\mathrm{N} / \mathrm{L}\right)$ & $<0,002$ & $0,002-0,01$ & $0,01-0,05$ & $>0,05$ \\
\hline Nitrat azotu $\left(\mathrm{mg} \mathrm{NO}_{3}{ }^{-}-\mathrm{N} / \mathrm{L}\right)$ & $<5$ & $5-10$ & $10-20$ & $>20$ \\
\hline Toplam kjeldahl-azotu (mg/L) & 0.5 & 1.5 & 5 & $>5$ \\
\hline Toplam fosfor (mg P/L) & $<0,03$ & $0,03-0,16$ & $0,16-0,65$ & $>0,65$ \\
\hline \multicolumn{5}{|c|}{ C) $\dot{I}_{z}$ Elementler (Metaller) } \\
\hline Civa $(\mu \mathrm{g} \mathrm{Hg} / \mathrm{L})$ & $<0,1$ & $0,1-0,5$ & $0,5-2$ & $>2$ \\
\hline Kadmiyum $(\mu \mathrm{gCd} / \mathrm{L})$ & $\leq 2$ & $2-5$ & $5-7$ & $>7$ \\
\hline Kurşun $(\mu \mathrm{g} \mathrm{Pb} / \mathrm{L})$ & $\leq 10$ & $10-20$ & $20-50$ & $>50$ \\
\hline Bakır $(\mu \mathrm{g} \mathrm{Cu} / \mathrm{L})$ & $\leq 20$ & $20-50$ & $50-200$ & $>200$ \\
\hline Nikel $(\mu \mathrm{gNi} / \mathrm{L})$ & $\leq 20$ & $20-50$ & $50-200$ & $>200$ \\
\hline Çinko $(\mu \mathrm{gZn} / \mathrm{L})$ & $\leq 200$ & $200-500$ & $500-2000$ & $>2000$ \\
\hline \multicolumn{5}{|c|}{ D) Bakteriyolojik Parametreler } \\
\hline Fekalkoliform (EMS/100 mL) & $\leq 10$ & $10-200$ & $200-2000$ & $>2000$ \\
\hline Toplam koliform (EMS/100 mL) & $\leq 100$ & $100-20000$ & $20000-100000$ & $>100000$ \\
\hline Tehlikeli maddeler & \multicolumn{4}{|c|}{$\begin{array}{l}\text { Tehlikeli maddeler ve bu tabloda verilmeyen diğer kirleticiler konuyla ilgili ülke } \\
\text { envanteri (referans değerler) oluşturulduktan sonra, } 1 \text { Ocak 2015'den itibaren } \\
\text { değerlendirilecektir. }\end{array}$} \\
\hline
\end{tabular}

(a) Konsantrasyon veya doygunluk yüzdesi parametrelerinden sadece birisinin sağlanması yeterlidir.

(b) $\mathrm{pH}$ değerine bağlı olarak serbest amonyak azotu konsantrasyonu $0.02 \mathrm{mg} \mathrm{NH}_{3}{ }^{-} \mathrm{N} / \mathrm{L}$ değerini geçmemelidir.

(c) Kalite sınıflarına göre suların kullanım maksatları:

Sınıf I - Yüksek kaliteli su;

1) İçme suyu olma potansiyeli yüksek olan yüzeysel sular,

2) Yüzme gibi vücut teması gerektirenler dahil rekreasyonel maksatlar için kullanılabilir su,

3) Alabalık üretimi için kullanılabilir nitelikte su,

4) Hayvan üretimi ve çiftlik ihtiyacı için kullanılabilir nitelikte su,

Sınıf II - Az kirlenmiş su;

1) İçme suyu olma potansiyeli olan yüzeysel sular,

2) Rekreasyonel maksatlar için kullanılabilir nitelikte su,

3) Alabalık dışında balık üretimi için kullanılabilir nitelikte su,

4) Mer'i mevzuat ile tespit edilmiş olan sulama suyu kalite kriterlerini sağlamak şartıyla sulama suyu,

Sınıf III - Kirlenmiş su;

Gıda, tekstil gibi nitelikli su gerektiren tesisler hariç olmak üzere, uygun bir arıtmadan sonra su ürünleri yetiştiriciliği için kullanılabilir nitelikte su ve sanayi suyu,

Sınıf IV - Çok kirlenmiş su;

Sınıf III için verilen kalite parametrelerinden daha düşük kalitede olan ve üst kalite sınıfına ancak iyileştirilerek ulaşabilecek yüzeysel sular. 


\section{1. İstatistiksel Veri Dĕgerlendirme Yöntemleri}

30 Kasım 2012 tarih ve 28483 sayılı Resmi Gazete'de yayınlanan "Yüzeysel Su Kalitesi Yönetimi Yönetmeliği”nde su kalitesi sınıflandırmasında karakteristik değerin bulunmasında kullanılan istatistiksel veri değerlendirme yöntemleri Hazen, Weibull ve Logaritmik yöntemlerdir. Aşağıda Tablo 2'de bu yöntemlere ait istatistiksel veri değerlendirme formülleri verilmektedir.

Tablo 2. Su kalitesi sınıflandırmasında karakteristik değerin bulunmasında kullanılan istatistiksel yöntemler[11]

\begin{tabular}{|c|c|c|c|c|}
\hline Yöntem & Yüzde Kesri & Yüzdelik değer & & $\begin{array}{l}\text { \%95'lik değer için gerekli } \\
\text { minimum veri sayıs }\end{array}$ \\
\hline Hazen & $p=\frac{r-\frac{1}{2}}{n}$ & $P=100 \cdot\left(\frac{n-\frac{1}{2}}{n}\right.$ & $=100-\frac{50}{n}$ & 10 \\
\hline Weibull & $p=\frac{r}{n+1}$ & $P=100 \cdot\left(\frac{n}{n+1}\right)$ & $=\frac{100 \cdot n}{n+1}$ & 19 \\
\hline Logaritmik & $\begin{array}{l}p=0,95 \\
p=0,90\end{array}$ & \multicolumn{2}{|c|}{$\begin{array}{l}P=\log ^{-1}(\mu+1,65 \sigma) \\
P=\log ^{-1}(\mu+1.282 \sigma)\end{array}$} & Minimum 3 yıllık veri \\
\hline
\end{tabular}

r: Sıra no (küçükten büyüğe doğru), p: Yüzde kesri, P: Yüzdelik değer, n: Veri sayısı

(a) Hazen yönteminin uygulama adımları

(1) $\mathrm{n}$ adet su kalitesi verisi küçükten büyüğe doğru sıralanır. Sıralanmış veri seti $X_{i}$ : i $=1,2, \ldots, n$ olarak adlandırılır.

(2) Seçilen yöntemin gerektirdiği asgari veri sayısı kontrol edilir. Yeterli veri mevcutsa, Hazen yönteminin uygulanmasına geçilir.

(3) Aşağıdaki ifadeler kullanılarak yüzde kesri (p) ve sıra numarası (r) hesaplanır; sıra numarası genellikle kesirli bir sayıdır.

Yüzde kesri: $p=\frac{r-\frac{1}{2}}{n} \quad$ Sira numarası: $r=p * n+\frac{1}{2}$

(4) Kesirli sıra numarasının bir altı ve üstündeki tam sayılara karşı gelen veriler arasında doğrusal enterpolasyon yapılarak, aşağıdaki ifade yardımıyla r'ye karşı gelen su kalitesi değeri $\left(X_{r}\right)$ hesaplanır.

$X_{r}=(1-f) \cdot X_{i}+f \cdot X_{i+1}$

$X_{i}$ : r'nin tam kısmı, f: r'nin ondalık kısmı

(b) Weibull yönteminin uygulama adımları

(1) $\mathrm{n}$ adet su kalitesi verisi kü̧̈ükten büyüğe doğru sıralanır. Sıralanmış veri seti $X_{i}: \mathrm{i}=1,2, \ldots, \mathrm{n}$ olarak adlandirilır.

(2) Seçilen yöntemin gerektirdiği asgari veri sayısı kontrol edilir. Yeterli veri mevcutsa, Weibull yönteminin uygulanmasına geçilir.

(3) Aşağıdaki ifadeler kullanılarak yüzde kesri (p) ve sıra numarası (r) hesaplanır; sıra numarası genellikle kesirli bir sayıdır.

Yüzde kesri: $\quad p=\frac{r}{n+1} \quad$ Sira numarası: $r=p *(n+1)$

(4) Kesirli sıra numarasının bir altı ve üstündeki tam sayılara karşı gelen veriler arasında doğrusal enterpolasyon yapılarak, aşağıdaki ifade yardımıyla r'ye karşı gelen su kalitesi değeri $\left(X_{r}\right)$ hesaplanır. 
$X_{r}=(1-f) \cdot X_{i}+f \cdot X_{i+1}$

$X_{i}$ : r'nin tam kısmı, $f$ : r'nin ondalık kısmı

(c) Logaritmik yönteminin uygulama adımları

(1) Seçilen yöntemin gerektirdiği asgari veri sayısı kontrol edilir. Yeterli veri mevcutsa, logaritmik yönteminin uygulanmasına geçilir.

(2) $\mathrm{n}$ adet su kalitesi verisi için (veri seti $\left.X_{i}: \mathrm{i}=1,2, \ldots, \mathrm{n}\right) \log 10\left(X_{i}\right)$ değerleri hesaplanır.

(3) Hesaplanan log $10\left(X_{i}\right)$ değerleri toplanarak T değeri hesaplanır.

(4) Aritmetik Ort. $(\mu)=\mathrm{T} / \mathrm{n}$ formülü kullanılarak aritmetik ortalama hesaplanır.

(5) Standart Sapma $(\sigma)=\sqrt{\frac{\Sigma(\log 10-\mu)^{2}}{\text { verisayısı-1 }}}$ formülü kullanılarak standart sapma hesaplanır.

(6) Bir su kalitesi parametresi ile ilgili veri seti için, logaritmik yönteme göre \%95'lik sınır değeri; \%95 değeri $=\log ^{-1}(\mu+1,65 \sigma)$ formülü kullanılarak hesaplanır.

(7) Bir su kalitesi parametresi ile ilgili veri seti için, logaritmik yönteme göre \%90’lık sınır değeri; \%90 değeri $=\log ^{-1}(\mu+1,1,282 \sigma)$ formülü kullanılarak hesaplanır.

\section{Bulgular}

Bu çalışmada, Sakarya Nehri üzerinde kurulu Pamukova, Doğançay ve Adatepe akım gözlem istasyonlarından 2012-2017 yılları arasında elde edilen su kalitesi verileri değerlendirilmiştir. Beş yıl ve 60 aylık ölçümden oluşan su kalitesi verileri genel şartlar (Sicaklık, pH, İletkenlik), oksijenlendirme parametreleri (Çözünmüş Oksijen, Biyolojik Oksijen İhtiyacı, Kimyasal Oksijen İhtiyac1) ve nütrient (besin elementleri) parametreleri (Amonyak Azotu, Nitrit Azotu, Nitrat Azotu, Toplam Kjeldahl Azotu, Toplam Fosfor)'ni içermektedir. Çalışma kapsamında 30 Kasım 2012 Tarih ve 28483 Sayll Resmi Gazete'de yayınlanan "Yüzeysel Su Kalitesi Yönetimi Yönetmeliği”nde yer alan Istatistiksel Veri Değerlendirme Yöntemleri (Hazen, Weibull ve Logaritmik yöntem) kullanılarak Sakarya Nehrinin belirtilen parametreler açısından su kalitesi sınıfları belirlenmiştir. Her bir istasyondan elde edilen veriler istatistiksel veri değerleme yöntemleri ile değerlendirilmiş ve elde edilen sonuçlar Tablo 1'de yer alan genel şartlar, oksijenlendirme parametreleri, nutrient (besin elementleri) parametreleri yönetmelik sınıd değerleri ile karşılaştırılmış ve Sakarya Nehri su kalitesi sınıfları belirlenmiştir. Aşağıdaki tablolarda her bir istasyon için elde edilen su kalitesi sınıf bulguları verilmektedir.

Tablo 3. Pamukova istasyonu su kalitesi sınıfının genel şartlar ve oksijenlendirme parametreleri açısından değerlendirilmesi

\begin{tabular}{cccc}
\hline \multicolumn{3}{c}{ Genel Şartlar } \\
\hline $\begin{array}{c}\text { Yöntem } \\
\text { Sinıf }\end{array}$ & $\begin{array}{c}\text { Sıcaklık } \\
\left({ }^{\circ} \mathbf{C}\right)\end{array}$ & $\mathbf{p H}$ & $\begin{array}{c}\text { Illetkenlik } \\
(\boldsymbol{\mu S} / \mathbf{c m})\end{array}$ \\
\hline Hazen & 25,18 & 8,50 & 1098,30 \\
Sinıf & III & II & III \\
Weibull & 25,40 & 8,50 & 1106,40 \\
Sinıf & III & II & III \\
Log \%95 & 28,89 & 8,53 & 1160,60 \\
Sinıf & III & III & III \\
Log \%90 & 24,86 & 8,41 & 1090,29 \\
Sinıf & II & II & III \\
\hline
\end{tabular}

\begin{tabular}{|c|c|c|c|}
\hline \multicolumn{4}{|c|}{ Oksijenlendirme } \\
\hline $\begin{array}{c}\text { Yöntem } \\
\text { Sinıf }\end{array}$ & $\begin{array}{c}\text { Çözünmüş } \\
\text { Oksijen } \\
\left(\mathbf{m g ~ O} \mathrm{O}_{2} / \mathrm{L}\right)\end{array}$ & $\begin{array}{c}\text { Biyolojik } \\
\text { Oksijen } \\
\text { İhtiyacı (BOİ) } \\
(\mathrm{mg} / \mathrm{l}) \\
\end{array}$ & $\begin{array}{c}\text { Kimyasal } \\
\text { Oksijen } \\
\text { İhtiyacı (KOİ) } \\
\text { (mg/l) } \\
\end{array}$ \\
\hline Hazen & 12,335 & 8 & 62,16 \\
\hline Sinıf & I & II & III \\
\hline Weibull & 12,38 & 8 & 62,79 \\
\hline Sinıf & I & II & III \\
\hline $\log \% 95$ & 12,23 & 7,077 & 58,83 \\
\hline Sinıf & I & II & III \\
\hline $\log \% 90$ & 11,71 & 5,86 & 50,64 \\
\hline Sinıf & $\mathrm{I}$ & II & III \\
\hline
\end{tabular}


Tablo 3'deki sonuçlar incelendiğinde, Pamukova istasyonu için üç yöntemden (Hazen, Weibull, Logaritmik) elde edilen sonuçlar yönetmelik değerleri ile karşılaştırıldığında genel şartlar açısından su kalitesinin III. sınıf bir su olduğu anlaşılmaktadır. Benzer şekilde oksijenlendirme parametresi açısından da su kalitesinin III. sınıf bir su olduğu görülmektedir.

Tablo 4. Pamukova istasyonu su kalitesi sınıfının nütrient (besin elementleri) parametreleri açısından değerlendirilmesi

\begin{tabular}{|c|c|c|c|c|c|}
\hline \multicolumn{6}{|c|}{ Nütrient (Besin Elementleri) Parametreleri } \\
\hline $\begin{array}{c}\text { Yöntem } \\
\text { Sinıf }\end{array}$ & $\begin{array}{c}\text { Amonyak Azotu } \\
\left(\mathrm{mg} \mathrm{NH}_{4}{ }^{+}-\mathrm{N} / \mathbf{L}\right)\end{array}$ & $\begin{array}{c}\text { Nitrit Azotu } \\
\left(\mathrm{mg} \mathrm{NO}_{2}^{-}-\mathrm{N} / \mathrm{L}\right)\end{array}$ & $\begin{array}{c}\text { Nitrat Azotu } \\
\left(\mathrm{mg} \mathrm{NO}_{3}^{-}-\mathrm{N} / \mathrm{L}\right)\end{array}$ & $\begin{array}{c}\text { Toplam Kjeldahl } \\
\text { Azotu (mg/L) } \\
\end{array}$ & $\begin{array}{l}\text { Toplam Fosfor } \\
\text { (mg P/L) }\end{array}$ \\
\hline Hazen & 0,45 & 0,16 & 4 & 1,15 & - \\
\hline Sinıf & II & IV & I & II & - \\
\hline Weibull & 0,49 & 0,165 & 4 & 2,18 & - \\
\hline Sinıf & II & IV & I & III & - \\
\hline $\log \% 95$ & 0,72 & 0,093 & 4,25 & 1,40 & 0,47 \\
\hline Sinıf & II & IV & I & II & III \\
\hline $\log \% 90$ & 0,49 & 0,071 & 3,65 & 1,05 & 0,46 \\
\hline Sinıf & II & IV & I & II & III \\
\hline
\end{tabular}

Tablo 4'deki sonuçlar incelendiğinde, Pamukova istasyonu su kalitesinin nütrient parametreleri açısından IV. sınıf bir su olduğu anlaşılmaktadır.

Tablo 5. Doğançay istasyonu su kalitesi sınıfının genel şartlar ve oksijenlendirme parametreleri açısından değerlendirilmesi

\begin{tabular}{cccc}
\hline \multicolumn{4}{c}{ Genel Şartlar } \\
\hline $\begin{array}{c}\text { Yöntem } \\
\text { Sinıf }\end{array}$ & $\begin{array}{c}\text { Sicaklık } \\
\left({ }^{\mathbf{0}} \mathbf{C}\right)\end{array}$ & $\mathbf{p H}$ & $\begin{array}{c}\text { İletkenlik } \\
(\boldsymbol{\mu} S / \mathbf{c m})\end{array}$ \\
\hline Hazen & 24,65 & 8,4 & 1094,6 \\
Sinıf & I & III & III \\
Weibull & 24,9 & 8,4 & 1104,5 \\
Sinıf & I & III & III \\
Log \%95 & 27,66 & 8,61 & 1263,32 \\
Sinıf & III & III & III \\
Log \%90 & 22,06 & 8,36 & 1098,51 \\
Sinıf & I & III & III \\
\hline
\end{tabular}

\begin{tabular}{cccc}
\hline \multicolumn{4}{c}{ Oksijenlendirme } \\
\hline $\begin{array}{c}\text { Yöntem } \\
\text { Sınıf }\end{array}$ & $\begin{array}{c}\text { Çözünmüş } \\
\text { Oksijen } \\
(\mathbf{m g ~ O} \text { O/L) }\end{array}$ & $\begin{array}{c}\text { Biyolojik } \\
\text { Oksijen } \\
\text { İhtiyacı (BOİ) } \\
\text { (mg/l) }\end{array}$ & $\begin{array}{c}\text { Kimyasal } \\
\text { Oksijen } \\
\text { İhtiyacı (KOI) } \\
\text { (mg/l) }\end{array}$ \\
\hline Hazen & 11,83 & 6,3 & 61,8 \\
Sınıf & I & II & III \\
Weibull & 11,83 & 6,3 & 61,8 \\
Sinıf & I & II & III \\
Log \%95 & 26,64 & 62,11 & 752,93 \\
Sınıf & I & III & IV \\
Log \%90 & 20,58 & 31,61 & 375,91 \\
Sınıf & I & III & IV \\
\hline
\end{tabular}

Tablo 5'deki sonuçlar incelendiğinde, Doğançay istasyonu için üç yöntemden (Hazen, Weibull, Logaritmik) elde edilen sonuçlar yönetmelik değerleri ile karşılaştırıldığında genel şartlar açısından su kalitesinin III. sınıf bir su olduğu anlaşılmaktadır. Benzer şekilde oksijenlendirme parametresi açısından su kalitesinin IV. sınıf bir su olduğu görülmektedir.

Tablo 6'daki sonuçlar incelendiğinde, Doğançay istasyonu su kalitesi nütrient parametreleri 
açısından değerlendirildiğinde su kalitesinin IV. sınıf bir su olduğu anlaşılmaktadır.

Tablo 6. Doğançay istasyonu su kalitesi sınıfının nütrient (besin elementleri) parametreleri açısından değerlendirilmesi

\begin{tabular}{ccccc}
\hline \multicolumn{5}{c}{ Nütrient } \\
\hline $\begin{array}{c}\text { Yöntem } \\
\text { Sinıf }\end{array}$ & $\begin{array}{c}\text { Amonin Elementleri) Parametreleri } \\
\left(\mathbf{m g ~ N H}_{4}{ }^{+}-\mathbf{N} / \mathbf{L}\right)\end{array}$ & $\begin{array}{c}\text { Nitrit Azotu } \\
\left(\mathbf{m g ~ N O}^{-}-\mathbf{N} / \mathbf{L}\right)\end{array}$ & $\begin{array}{c}\text { Nitrat Azotu } \\
\left(\mathbf{m g ~ N O}^{-}-\mathbf{N} / \mathbf{L}\right)\end{array}$ & $\begin{array}{c}\text { Toplam Kjeldahl Azotu } \\
(\mathbf{m g} / \mathbf{L})\end{array}$ \\
\hline Hazen & 0,453 & 0,142 & 3,93 & 0,997 \\
Sinıf & II & IV & I & II \\
Weibull & 0,485 & 0,1875 & 3,98 & 1,01 \\
Sinıf & II & IV & I & II \\
Log \%95 & - & - & 32,14 & 30,73 \\
Sinıf & - & - & IV & IV \\
Log \%90 & - & - & 18,58 & 12,36 \\
Sinıf & - & - & III & IV \\
\hline
\end{tabular}

Tablo 7'deki sonuçlar incelendiğinde, Adatepe istasyonu için üç yöntemden (Hazen, Weibull, Logaritmik) elde edilen sonuçlar yönetmelik değerleri ile karşılaştırıldığında genel şartlar açısından su kalitesinin III. sınıf bir su olduğu anlaşılmaktadır. Benzer şekilde oksijenlendirme parametresi açısından su kalitesinin IV. sınıf bir su olduğu görülmektedir.

Tablo 7. Adatepe istasyonu su kalitesi sınıfının genel şartlar ve oksijenlendirme parametreleri açısından değerlendirilmesi

\begin{tabular}{cccc}
\hline \multicolumn{4}{c}{ Genel Şartlar } \\
\hline $\begin{array}{c}\text { Yöntem } \\
\text { Sinıf }\end{array}$ & $\begin{array}{c}\text { Sıcaklık } \\
\left({ }^{\circ} \mathbf{C}\right)\end{array}$ & $\mathbf{p H}$ & $\begin{array}{c}\text { Illetkenlik } \\
(\boldsymbol{\mu S} / \mathbf{c m})\end{array}$ \\
\hline Hazen & 25,85 & 8,33 & 1023,5 \\
Sinıf & III & I & III \\
Weibull & 26 & 8,35 & 1025,75 \\
Sinıf & III & I & III \\
Log \%95 & 21,59 & 8,30 & 990,33 \\
Sinıf & I & I & II \\
Log \%90 & 16,59 & 8,10 & 864,91 \\
Sinıf & I & I & II \\
\hline
\end{tabular}

\begin{tabular}{|c|c|c|c|}
\hline \multicolumn{4}{|c|}{ Oksijenlendirme } \\
\hline $\begin{array}{c}\text { Yöntem } \\
\text { Sinıf }\end{array}$ & 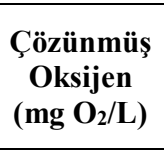 & $\begin{array}{c}\text { Biyolojik } \\
\text { Oksijen } \\
\text { İhtiyacı (BOİ) } \\
(\mathrm{mg} / \mathrm{l}) \\
\end{array}$ & $\begin{array}{c}\text { Kimyasal } \\
\text { Oksijen } \\
\text { İhtiyacı (KOİ) } \\
\text { (mg/l) } \\
\end{array}$ \\
\hline Hazen & 12,10 & 6,00 & 77,17 \\
\hline Sinıf & I & II & IV \\
\hline Weibull & 12,10 & 6,03 & 78,76 \\
\hline Sinıf & I & II & IV \\
\hline $\log \% 95$ & 23,93 & 16,88 & 542,59 \\
\hline Sinıf & I & III & IV \\
\hline $\log \% 90$ & 19,13 & 11,97 & 286,12 \\
\hline Sinıf & $\mathrm{I}$ & III & IV \\
\hline
\end{tabular}

Tablo 8'deki sonuçlar incelendiğinde, Adatepe istasyonu su kalitesi nütrient parametreleri açısından değerlendirildiğinde, su kalitesinin IV. sınıf bir su olduğu anlaşılmaktadır. 
Tablo 8. Adatepe istasyonu su kalitesi sınıfının nütrient (besin elementleri) parametreleri açısından değerlendirilmesi

\begin{tabular}{cccc}
\hline \multicolumn{4}{c}{ Nütrient (Besin Elementleri) Parametreleri } \\
\hline $\begin{array}{c}\text { Yöntem } \\
\text { Sinıf }\end{array}$ & $\begin{array}{c}\text { Nitrit Azotu } \\
\left(\mathbf{m g ~ N O}^{-}-\mathbf{N} / \mathbf{L}\right)\end{array}$ & $\begin{array}{c}\text { Nitrat Azotu } \\
\left(\mathbf{m g ~ N O}^{-}-\mathbf{N} / \mathbf{L}\right)\end{array}$ & $\begin{array}{c}\text { Toplam Kjeldahl Azotu } \\
(\mathbf{m g} / \mathbf{L})\end{array}$ \\
\hline Hazen & 0,109 & 4 & 0,2 \\
Sinıf & IV & $\mathrm{I}$ & $\mathrm{I}$ \\
Weibull & 0,033 & 4 & 0 \\
Sinıf & III & I & I \\
Log \%95 & 0 & 4,07 & 0 \\
Sinıf & I & I & I \\
Log \%90 & 0 & 3,61 & 0 \\
Sinıf & I & I & I \\
\hline
\end{tabular}

\section{Sonuçlar ve Tartışma}

Bu çalışmada, Sakarya Nehri su kalitesi sınıflarının belirlenmesinde nehir üzerinde yer alan 3 ayrı akım gözlem istasyonundan (Pamukova, Doğançay ve Adatepe) 2012-2017 yılları arasında elde edilen su kalitesi verileri kullanılmıştır. 5 yıllık (60 aylık) verilerin değerlendirilmesinde "30 Kasım 2012 tarih ve 28483 sayll Resmi Gazete’de yayınlanan Yüzeysel Su Kalitesi Yönetimi Yönetmeliği'nde" yer alan istatistiksel veri değerlendirme yöntemleri (Hazen, Weibull, Logaritmik Yöntem) kullanılmıştır. Sakarya Nehri su kalite sınıfları Tablo 1'de sunulan ve aynı yönetmeliğin Ek-5'inde yer alan "Kıtaiçi Yüzeysel Su Kaynaklarının Sinıflarına Göre Kalite Kriterleri" esas alınarak belirlenmiştir. Her bir istasyondan elde edilen veriler yönetmelikte yer alan genel şartlar, oksijenlendirme parametreleri, nutrient (besin elementleri) parametreleri açısından istatistiksel veri değerlendirme yöntemleri kullanılarak değerlendirilmiş ve su kalitesi sınıfları belirlenmiştir.

Sonuç olarak üç yöntemden (Hazen, Weibull, Logaritmik) elde edilen sonuçlar Tablo 1'de yer alan yönetmelik sınır değerleri ile karşılaştırıldığında;

> Pamukova istasyonu su kalitesinin genel şartlar açısından III. sınıf, oksijenlendirme parametresi açısından III. sınıf, nütrient parametreleri açısından IV. sınıf bir su olduğu,

$>$ Doğançay istasyonu su kalitesinin genel şartlar açısından III. sınıf, oksijenlendirme parametresi açısından IV. sınıf, nütrient parametreleri açısından IV. sınıf bir su olduğu,

Adatepe istasyonu su kalitesinin genel şartlar açısından III. sınıf, oksijenlendirme parametresi açısından IV. sınıf, nütrient parametreleri açısından IV. sınıf bir su olduğu anlaşılmıştır.

Ayrıca “Yüzeysel Su Kalitesi Yönetimi Yönetmeliği’nde” yer alan istatistiksel veri değerlendirme yöntemlerinin (Hazen, Weibull, Logaritmik Yöntem) nehir su kalitesinin değerlendirilmesinde pratik, anlaşılabilir ve kolay yorumlanabilir yöntemler olduğu görülmüştür. 


\section{Teşekkür}

Bu çalışma Sakarya Üniversitesi Bilimsel Araştırma Projeleri Koordinasyon Birimi tarafından 2014-50-01-046 nolu proje kapsamında desteklenmiştir

\section{Referanslar}

[1] Ewaid SH, Abed SA, Kadhum SA. Predicting the Tigris River water quality within Baghdad, Iraq by using water quality index and regression analysis. Environ Technol Innov 2018; 11: 390-398.

[2] Nguyen TT, Keupers I, Willems P. Conceptual river water quality model with flexible model structure. Environ Model Softw. Epub ahead of print 2018. DOI: 10.1016/j.envsoft.2018.03.014.

[3] Noori R, Berndtsson R, Hosseinzadeh M, et al. A critical review on the application of the National Sanitation Foundation Water Quality Index. Environ Pollut 2019; 244: 575-587.

[4] Ponsadailakshmi S, Ganapathy Sankari S, Prasanna SM, et al. Evaluation of water quality suitability for drinking using drinking water quality index in Nagapattinam district, Tamil Nadu in Southern India. Groundw Sustain Dev 2018; 6: 43-49.

[5] Tripathi M, Singal SK. Use of Principal Component Analysis for parameter selection for development of a novel Water Quality Index: A case study of river Ganga India. Ecol Indic 2019; 96: 430-436.

[6] Dede ÖT, Sezer M. Aksu Deresi Su Kalitesinin Belirlenmesinde Kanada Su Kalitesi İndeks (CWQI) Modelinin Uygulanması. Gazi Üniversitesi Mühendislik-Mimarlık Fakültesi Derg 2017; 32: 909-917.

[7] Isik S, Dogan E, Kalin L, et al. Effects of anthropogenic activities on the Lower Sakarya River. Catena 2008; 75: 172-181.

[8] Şengörür B, İsa D. Sakarya Nehri’ne Ait Su Kalite Gözlemlerinin Faktör Analizi. Turk J Engin Env Sci 2001; 25: 415-425.

[9] Anıl Kızılaslan M, Sağın F, Doğan E, et al. Aşağı Sakarya Nehri akımlarının yapay sinir ağları ile tahmin edilmesi. SAU J Sci 2014; 18: 99-103.

[10] Atalay A. Sakarya Nehri'nin Aylık ve Yıllık Akım Değerlerinin İstatistiksel Analizi ve Yağış Tutarları ile Korelasyonu. Sakarya Üniversitesi, Fen Bilimleri Enstitüsü, 2008.

[11] Orman ve Su İşleri Bakanlığı. Yüzeysel Su Kalitesi Yönetimi Yönetmeliği. 2012. 